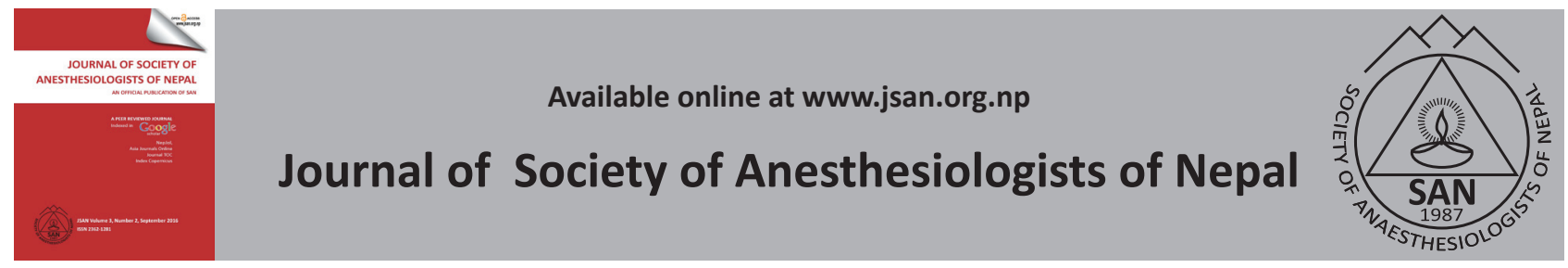

Viewpoint

\title{
Do patients in developing world get dignified anesthetic care? Hem Raj Joshi
}

Nepal Medical College Pvt Ltd (NMC), Attarkhel, Jorpati, Kathmandu, 44602, Nepal

\author{
ARTICLE INFO \\ Article History \\ Received $18^{\text {th }}$ February 2017 \\ Accepted $18^{\text {th }}$ February 2017 \\ Published $28^{\text {th }}$ June 2017 \\ (C) Authors retain copyright \\ and grant the journal right of \\ first publication with the work \\ simultaneously licensed under \\ Creative Commons Attribution \\ License CC - BY 4.0 that allows \\ others to share the work with \\ an acknowledgement of the \\ work's authorship and initial \\ publication in this journal.
}

\begin{abstract}
Background: This article shares the experiences of two patients undergoing a colonoscopy without any sedation or anaesthesia. The author raises the question whether patients from the developing countries get proper treatment options while undergoing invasive procedures which may require sedation or anaesthesia.
\end{abstract}

Keywords: anaesthesia; colonoscopy; developing countries; low and middle income countries; sedation

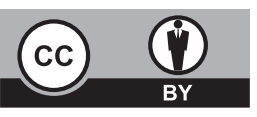

How to cite this article: Joshi HR. Do patients in developing world get dignified treatment? Journal of Society of Anesthesiologists of Nepal (JSAN) 2017;4(1):3-4. https://doi.org/10.3126/jsan.v4i1.17376

$T^{n}$ he public expects high-quality evidence-based treatment from their health care providers. Physicians should be ready to provide the compassionate and humane care to individual patients. They should always be respectful of autonomy and dignity of the fellow human being. They should explain their method of treatment, potential problems, possible benefits, and provide the patient with informed choices. With any surgical or medical procedure, consent should be obtained from all the patients. A valid informed consent is based on knowledge of the possibility of treatment options, the associated risks and offered benefits of each option, and the likelihood that these will occur for the individual patient and the patients will make choices based on the options. It is a legal document and has been recommended for use by the Government of the federal democratic Republic of Nepal. However, I would

\footnotetext{
Corresponding Author:

Dr Hem Raj Joshi, MD

Lecturer, Department of Anaesthesiology,

Nepal Medical College Pvt Ltd (NMC), Attarkhel,

Jorpati, Kathmandu, 44602, Nepal

Email: hemraj_joshi@yahoo.com

Orcid ID: http://orcid.org/0000-0003-3316-2842
} 
like to share two stories where the patients had to endure considerable suffering during routine screening procedure called colonoscopy.

The colonoscope is a flexible tube with a telescope that is inserted into the back passage to assess the large intestine. Professional bodies recommend that all the individuals who are 50 years or older should receive the colonoscopy every 10 years because the procedure could detect cancer in early stage and treatment could be done relatively easily.

No choices: Both individuals were undergoing colonoscopy for the first time. Colonoscopy can be done under sedation or without sedation. They were not given the choice and the procedure was done when they were completely awake. It is true that some patients can tolerate the procedure without sedation, but many do not. These patients belonged to the latter group. Despite the patient's repeated request to stop the procedure because of unbearable pain, it was performed with some physical restraints in a tertiary care centre in Kathmandu. They left the hospital with very bad experience.

Worse than labour pain: "It was the worst experience of life. I have had baby births. Nature is more generous and she gives you moments of rest during the labour. But colonoscopy was worse than labour. If someone asks me, I will definitely tell them that how bad it was. I have no plans to go for colonoscopy anymore." The husband testifies," My wife was shaken to the core. I heard her screaming inside the procedure room. They did not let me go there." He adds, "I also had a colonoscopy. It was a very unpleasant experience. They did not give me pain or sleeping injections."

Lack of imagination: In the hospital where complex surgeries such as open heart surgeries, neurosurgeries are routinely done; I wonder why the patients do not get the choice of twilight anaesthesia or conscious sedation during a routine procedure such as colonoscopy. Such a bad experience not only deters the concerned individuals to repeat the procedure but also scares the public as well. I also question the compassion and lack of imagination of the physicians who perform the procedures. I believe that the physician certainly had a good intention to diagnose the disease, but could they conceive that their actions can be counterproductive? Susceptible individuals can even develop post-traumatic stress disorder. And it may impair the doctor-patient relationship which is the foundation of medicine. The patients may rightly feel that they do not receive the care they deserve. Certainly, no physician would like to be called as an uncaring person.

There are many reports that so-called minor procedures such as termination of pregnancy are also performed without pain medications. There can be an argument that procedure without sedation could help to avoid the harmful effect of sedative and anaesthetic agents. But in my opinion, if a patient wishes for sedation during the procedure, it is inhumane to put a patient through barbaric and painful treatment when relatively safe medications and appropriate expertise is available. I would like to plea the professional bodies and individual physicians of Nepal that the patients are offered the choices of general anaesthesia, conscious sedation or no sedation during the procedures such as colonoscopy, and termination of pregnancy. As a medical professional, we can make the real difference in the patient's life. Let's offer them the choices, explain them the advantages and disadvantages of each method and care them with utmost dignity. Let the patients decide what the right choice is for them.

Conflicts of interest: Dr Joshi has filled the ICMJE conflict of Interest form and declare that he has no conflict of interests with respect to this article.

\section{Acknowledgement: None}

Sources of Funding: None

ORCID ID:

Hem Raj Joshi http://orcid.org/0000-0003-3316-2842 